\title{
The Status of Mental Health Promotion
}

\author{
Helen Herrman, MD, ${ }^{1,2}$ \\ Eva Jané-Llopis, $\mathrm{PhD}^{3}$
}

\begin{abstract}
Mental health is a state of wellbeing in which a person can use his or her own abilities and cope with the normal stresses of life. Mental health has a central place in global public health and public health in all countries. Poor mental health is associated with social inequality and social disconnection. Good mental health contributes to human, social and economic development. There are strong interconnections between mental and physical health and behaviour. Concepts closely related to mental health include wellbeing, a broader concept, and resilience. Resilience is a dynamic concept referring to a person's ability to maintain or regain health after exposure to adversity. Mental health and resilience both depend on interactions between personal characteristics and social factors such as safety and access to education and work.

Health promoting actions support people to adopt healthy ways of life and create living conditions and environments conducive to health. Improving the mental health of a population requires a comprehensive approach to promoting mental health alongside prevention and treatment of mental ill health. Actions that promote mental health and prevent mental illnesses may overlap.

The field of mental health promotion is evolving rapidly. Several countries are introducing evidence-based and cross-government policies and programs to promote wellbeing. Evidence is emerging on the cost-effectiveness of a number of these interventions; in parenting, schools, workplaces, older age, and other social support domains. Experience is growing on the development of partnerships and implementation in countries, the links between mental health and human rights, and the need for mental health promotion in low-income countries and in disaster situations and other emergencies. Continuing innovation, adaptation and evaluation of programs is now required, especially in low-income countries, to integrate mental health promotion in the public health agenda of countries worldwide.
\end{abstract}

\footnotetext{
${ }^{1}$ Orygen Youth Health Research Centre and the Centre for Youth Mental Health, The University of Melbourne, Australia.

${ }^{2}$ Director, World Health Organization Collaborating Centre in Mental Health, Melbourne, Australia.

${ }^{3}$ World Economic Forum, Geneva, Switzerland.

Corresponding Author Contact Information: Professor Helen Herrman at h.herrman@ unimelb.edu.au; Orygen Youth Health Research Centre, Centre for Youth Mental Health, The University of Melbourne, Locked Bag 10, Parkville, Victoria 3052, Australia.
} 
Key Words: Mental health promotion, wellbeing, resilience, psychosocial programs, prevention, human rights

Suggested Citation: Herrman H, Jané-Llopis E. The status of mental health promotion. Public Health Reviews. 2012;34: epub ahead of print.

\begin{abstract}
"Positive mental health is linked to a range of development outcomes and is fundamental to coping with adversity. On the other hand, poor mental health impedes an individual's capacity to realize their potential, work productively, and make a contribution to their community. In order to improve population mental health, countries need to implement effective treatment, prevention, and promotion programs that are available to all people who need them."
\end{abstract}

World Health Organization ${ }^{1}$

\title{
INTRODUCTION
}

A solid body of evidence, as assembled by the World Health Organization Commission on Macroeconomics and Health and the 1993 World Development Report, links health and wealth. ${ }^{2}$ In any given society, in countries of all types, individuals, families and communities with fewer financial and educational resources have worse health and wellbeing than those with better financial and educational resources; and jurisdictions that are more equal do better in terms of health and wellbeing, as well as in terms of productivity. $^{3}$ The Millennium Development Goals (MDGs) place a central focus on public health, recognising that improving health is required to break the vicious cycle of poverty and poor health in the world's poorest countries, and conversely, improving socio economic conditions improves health. ${ }^{4}$

This body of evidence is central to advocacy for a series of global health initiatives in recent years, including those linked with the MDGs. ${ }^{5}$ Despite its current lack of prominence in some of these programs, ${ }^{6}$ mental health has a central place in global public health, and in public health wherever it is practised. Several lines of work support this assertion. First is evidence of the interactions between mental health, health, behaviour and relative social disadvantage in any country.,8 Impoverished and socially disorganized neighbourhoods have a powerful adverse effect on mental health. ${ }^{7,9}$ Second there is the specific evidence of close links between mental health and development, in its individual, community and economic meanings..$^{8,10,11}$ Third is the growing evidence and realisation that positive mental health has biological, developmental and social roots, and that it is 
the universal basis of human connection. ${ }^{12}$ Combined with the broader evidence on the social determinants of health, these bodies of work contribute to understanding the relationship between social conditions and mental and physical health: this provides a foundation for actions promoting mental health as well as complementary strategies in prevention and treatment of mental ill health. ${ }^{13}$ Even though arguments about health and economic productivity are important, the moral as well as practical value of mental health is the basis of advocacy for promoting mental health. ${ }^{14,15}$

Promoting mental health requires the full range of public health and clinical actions, equivalent to, and overlapping with those needed for promotion of health in all its aspects. ${ }^{16-18}$ Introducing these actions depends on the base of community support; and developing and maintaining partnerships required for implementation, as in all public health work. ${ }^{19}$ Promoting mental health in any country or community thereby requires that the leaders and people in the communities understand the value of mental health and the options for its promotion. ${ }^{14}$

\section{Concepts and definitions}

Mental health is a set of positive attributes. It is defined by WHO as "a state of wellbeing in which the individual realizes his or her own abilities, can cope with the normal stresses of life, can work productively and fruitfully, and is able to contribute to his or her community". ${ }^{20}$ Mental health is intrinsic to health; it is more than the absence of mental illness; and it is intimately connected with physical health and behaviour. These ideas are implicit in the well-known definition of health used by WHO: "a state of complete physical, mental and social wellbeing and not merely the absence of disease or infirmity".

The attributes defining mental health are universal. However, their expression differs culturally and in different contexts; and sensitivity to the factors valued by each culture and across varying political, economic, and social settings, increases the relevance and success of interventions. ${ }^{21}$ Those developing interventions in any country or community will need to find out, for example, how discrimination affects the lives of women or indigenous populations in that community, or the way that local groups of young people are using information technology. Positive mental health needs to be defined in terms that are culturally sensitive and inclusive, and its criteria validated through empirical and longitudinal study. ${ }^{12}$

Various names are used for closely related concepts. The term wellbeing is included in the WHO definition of mental health and at times is considered to be synonymous with it. However, there are some differentiations in the 
understanding of wellbeing. Its meaning varies from a sense of physical, mental and social health to definitions that include economic and development variables. Wellbeing as a concept was already well developed by Aristotle, who made a distinction between a moral life, which was necessary to maintain happiness, and a material life, which was necessary to meet basic needs. He considered wellbeing as multidimensional, with both material and immaterial dimensions. He also believed that successful communities should share common principles on what is important for wellbeing and that consultation was essential to develop consensus on what leads to the good life. Today's definitions of wellbeing reflect modern science as well as the ancient contributions of Aristotle. The Oxford English dictionary definition, for example, is: the state of being or doing well in life; happy, healthy or prosperous condition; moral or physical welfare (of a person or community).

\section{Wellbeing and mental health on the global agenda}

The science of wellbeing has grown over the past 30 years with contributions from psychology, sociology, economics, medicine and other fields. Only recently has there been a corresponding level of interest from national and international advocates and policymakers. Documents and projects from the Organisation for Economic Co-operation and Development (OECD), the World Economic Forum, the New Economics Foundation and the French and United Kingdom governments consider the causes, feedback effects and indicators of wellbeing. ${ }^{22-24}$ The government of Bhutan famously declared happiness as a national goal some years ago; using the term happiness in a similar way. Advocates and cynics alike note the political focus on the roots and positive feedback effects of wellbeing in terms of better performance at work, in families, and in the community. Wellbeing is proposed as a routine statistical indicator of national performance alongside economic growth. ${ }^{24}$ All member states in the latest Rio+20 declaration from the United Nations Conference on Sustainable Development, committed to a series of measures to improve the wellbeing of the planet and its inhabitants, including the need to take steps to go beyond gross domestic product (GDP). ${ }^{25}$

\section{Influences on mental health}

Social inequality is closely linked with mental ill health, as well as ill health of any type. ${ }^{26-28}$ Relative positions in society affect health, exposure to illness and risk for illness-producing behaviours. ${ }^{3,7,26}$ Evidence from different parts of the world over several decades also shows that an adverse economic climate is associated with poor mental health. ${ }^{29}$ Poverty, social disadvantage, human rights abuses and social exclusion have detrimental effects on the health and mental health of people worldwide. ${ }^{7,28,30,31}$ 
The WHO Commission on the Social Determinants of Health (CSDH) documents social gradients in health in all regions, with the poorest in any community having much worse health than those who are socioeconomically advantaged..$^{32}$ As mental health is integral to health, the report directs attention to the social determinants of mental health and the needs for mental health promotion associated with these. The Commission calls for a 'new global agenda for health equity' emphasising in its recommendations the importance of early childhood development and complete education for girls as well as boys.

Mental health promotion requires comprehensive knowledge of the determinants of mental health and mental health problems-structural determinants including poverty and gender, and the conditions of daily life-and identification of those that are modifiable, so that they can be targeted through interventions of various types. The factors that contribute to mental health can be grouped into three elements: the individual, his or her society, and the cultural and political environment. ${ }^{33}$ Environmental factors include: adequate housing; domestic and public safety; access to good education for all; fair working conditions and legal recognition of rights to freedom from discrimination. Social factors include: the benefits of strong early emotional attachments; access to secure relationships with affection and trust; and abilities to communicate, negotiate and participate. Individual determinants include: capacities to regulate emotions and thoughts; to learn from experience; to manage conflict; and to tolerate life's unpredictability.

\section{The importance of mental health}

Mental health is intimately connected with physical health and behaviour, ${ }^{7}$ as well as educational performance, employment and crime reduction. ${ }^{16-18}$ It contributes to human, social and economic development, and helps people and communities reach their potential. ${ }^{34}$ It makes a crucial contribution in society to prosperity, solidarity, social justice, and quality of life. ${ }^{29}$ Recent evidence on the neurobiology of positive emotions, such as empathy, compassion, and parental love, essential to human connection and spirituality and to the nurturing of future generations, indicates that these emotions are governed by limbic structures. ${ }^{12}$ Yet, in most countries of the world, health programs give relatively little attention to mental health and mental illness. ${ }^{35}$ This is associated with a conceptual failure to recognise the value of mental health to the individual and community ${ }^{14}$ as well as failure to recognise the humanity and dignity of those living with mental illness. ${ }^{36-38}$ The recent attention to this agenda under the rubric of wellbeing and its early inclusion in national policymaking as noted above is a significant development for the field. 


\section{Resilience and mental health}

Resilience is an interactive concept, referring to a relative resistance to environmental risk experiences, or the overcoming of stress or adversity, and it is thus differentiated from positive mental health. ${ }^{39}$ The vulnerability or resilience of any child or adult in the face of adversity is determined by a complex interplay of individual attributes and the social context. ${ }^{40,41}$ While positive stress is important for healthy development, resilience is more likely to be acquired or present when a child or adult can avoid strong, frequent, or prolonged stress, or when the effects are buffered by supportive relationships. ${ }^{42}$ Supportive, sensitive early caregivers in infancy and childhood can increase resilience and reduce the effects of "toxic" environments ${ }^{43}$ or major trauma such as a natural disaster. Mental health promoting interventions have the possibility to increase resilience for people with experience of adversities. As in all fields of health, clinical treatment and broader health promoting interventions each have a role in improving the chances of resilience among children and adults affected by maltreatment, interpersonal violence, a state of community emergency or other sources of severe adversity..$^{40}$ Individual resilience also is seen as critical to support community resilience and create supportive environments and communities that are prepared to jointly address and positively face new challenges. ${ }^{44}$

\section{Promoting mental health}

Like promotion of physical health, mental health promotion involves actions that support people to adopt and maintain healthy ways of life and create living conditions and environments that allow or foster health. It refers to the mental health of everybody in the community, including those with no experience of mental illness as well as those who live with illness and disability. Much of the work is done outside the health sector, however health practitioners have important roles as advocates and advisers to introducing the policies and programs. ${ }^{16}$

Some health promoting interventions have the primary goal of promoting mental health, such as those that support mothers with mental illness to care for their children (targets specifically to promote the mental health of the children), and those to promote mental health of school children or elderly in frail conditions. Others are mainly intended to achieve something else but improve mental health as a side benefit. The latter include activities designed to reduce misuse of tobacco, alcohol and other drugs, to reduce harm from unsafe sex, to improve the relationships between teachers and students in schools, or to alleviate social and economic problems such as crime and intimate partner violence. Suicide prevention 
programs in countries or districts will also typically include interventions that promote mental health.

Actions that promote health, prevent illness and disability, and support the treatment and rehabilitation of those affected can all contribute to improving mental health in a population. These are different from one another, even though the actions and outcomes overlap, and all are required. ${ }^{14}$ Health promotion conceptually is concerned with the determinants of health and prevention with the causes of ill health. The actions that promote mental health will often have as an important outcome the prevention of mental disorders; and those involved in prevention can operate at multiple levels, including population determinants as well as risk factor reduction. ${ }^{45}$ Mental health promotion refers to activities that go beyond (though may contribute to) preventing and treating illness. The need for population-based measures to promote mental health is illustrated by analogy with heart health. Population-based measures to encourage change in diet and exercise habits have made indispensable contributions over 30 years to containing the epidemic of heart disease and stroke in many countries. ${ }^{46}$

The Ottawa Charter for Health Promotion signed at the First International Conference on Health Promotion recommends strategies that can be applied usefully to promoting mental health. ${ }^{47}$ It considers the individual, social, and environmental factors that influence health. It emphasises the control of health by people in their everyday settings as well as healthy policy and supportive environments. The Charter's five strategies are: building healthy public policies, creating supportive environments, strengthening community action, developing personal skills, and reorienting health services.

Consistent with this, the activities or interventions in mental health promotion practice take place at several levels. Some are distant from the individual, or targeted at the whole population, such as policies to tax alcohol products and others are closer to the individual such as homevisiting health promotion programs.${ }^{14}$ The interventions may be designed to strengthen individuals, with an emphasis on vulnerable people such as displaced persons or malnourished children. They may be designed to strengthen communities (as in community development and neighbourhood renewal) or improve living and working conditions (e.g., adequate housing, improving food security and nutritional value, and making work conditions safer), with an emphasis on disadvantaged areas and specific sectors or settings respectively. Healthy policies aim to alter the macroeconomic or cultural environment to reduce poverty and the wider adverse effects of inequality on society. These include policies and regulations on legal and human rights, promoting cultural values, encouraging equal opportunities, tax policies and incentives, and hazard control. 
The foundation on which mental health promotion is built, as is all public health work, is support in national policies for promotion of well being and safety, and community partnerships for action. ${ }^{19}$ It requires researchers and practitioners to study and develop with care and sensitivity public support for research and for implementing effective interventions. ${ }^{19}$

\section{EVIDENCE FOR MENTAL HEALTH PROMOTION}

Sufficient evidence now exists to support the local application and evaluation of a range of policy and practice interventions to promote mental health. ${ }^{16-18,29}$ The DataPrev project financed by the European Commission summarises the evidence available about effective interventions for promoting positive mental health through parenting, in schools, at work, and in older ages, supported by economic analyses. ${ }^{29}$ The results show that a series of different types of interventions-ranging from psychological support to taxation, for different target groups and contexts - are promising in the promotion of mental health. All the evidence in each of these four domains was analyzed through reviews of existing systematic reviews and meta-analyses. Evidence for effective parenting interventions, for example, is based on a detailed analysis of 51 systematic reviews published in the scientific literature that were, in turn, systematically identified. ${ }^{29}$ Parenting is identified as the single most important factor contributing to a healthy start in life and hence to mental health and wellbeing, and health and function throughout life. ${ }^{29}$

There are numerous examples of effective interventions for supporting stimulation through parenting, which is now recognised as the single most important factor for building resilience in youth. ${ }^{48,49}$ The interventions include immediate skin-to-skin contact between baby and mother straight after delivery, ${ }^{50}$ breast feeding ${ }^{51}$ and carrying the baby in a pouch, by both mother and father. ${ }^{52}$ All such approaches to promoting psychosocial stimulation of babies and young infants have led to long-term educational and cognitive development and healthier development overall. ${ }^{53}$ However, these measures can vary significantly from one another and range from simple low cost practices (e.g., breast feeding) to more complex interventions requiring significant investment and planning (e.g., specialized visiting practices) ${ }^{29}$

Interventions that are more costly to implement include practices that prevent and treat postnatal depression (a group where detrimental effects on infant and child mental wellbeing and development are demonstrated), and a range of practices that target demographically and socially high-risk groups such as teenage parents. For example, multi component long-term 
home-visiting programs can be effective in improving parenting and parent and infant mental health outcomes as well as reducing child abuse. Longerterm studies spanning a generation have found even larger positive outcomes from parenting interventions that were missed in shorter-term studies. ${ }^{29}$

Policies and practices to support parenting in the general population and among those at greater risk can contribute to society in ways extending beyond better mental health and wellbeing; including social (e.g., reduced criminal convictions), educational (e.g., increased school achievement), and economic (e.g., attainment of better jobs later in life) outcomes. ${ }^{29}$ Most children experience a level of mental health that enables them to develop and participate in life according to community expectations; the evidence suggests that parenting support could further improve their mental wellbeing in childhood and adulthood. At the same time, the mental health of a significant proportion of children is significantly compromised by neglect, maltreatment and other adversities. ${ }^{54}$ The consequences of poor mental health in childhood increase the likelihood as an adult of low educational achievement, reduced productivity, criminality, and violence, as well as adult mental disorder, unhealthy lifestyles, and risk of ill health. ${ }^{29}$

The school is now seen as a community resource to promote mental, emotional, and social wellbeing. Partnerships of implementing agencies, research teams or prevention workers with schools and the education sector have been achieved with the understanding that mental, physical, and emotional wellbeing of young people are important for successful learning and retention in school; and that successful partnerships require cooperation with the school as a whole. Schools worldwide are engaging in a range of initiatives and policies related to mental health. Effective interventions are well designed and thoroughly implemented and their characteristics include: focusing on positive mental health; balancing approaches that are universal and targeted to children with identified problems; starting early with the youngest children and continuing with older ones; operating for a lengthy period of time; and embedding work within a multimodal, whole-school approach that includes changes to school ethos, teacher education, liaison with parents, parenting education, community involvement, and coordinated work with outside agencies. ${ }^{29}$

School-based programs tend to have a multi component nature addressing both physical and mental health to their mutual benefit. A similar situation exists with mental health programs at work, another area of intensive activity in recent decades; and befriending and other psychosocial programs to reduce social isolation among older people. ${ }^{29}$ Evidence exists for promoting mental health through other domains such as justice, urban 
and rural planning, and business. A recent domain of activity is understanding and using the internet as a setting for promoting mental health among young people, as well as support for young people in trouble..$^{55,56}$

The published evidence on cost-effectiveness is growing. ${ }^{57,58}$ Analyses conducted recently in the UK and United States indicate the benefits of a wide range of interventions that promote mental health. The interventions range from the prevention of childhood conduct disorder, practical measures to reduce the number of suicides, and wellbeing programs provided in the workplace.$^{58}$ Some of these interventions are a health service responsibility. Others highlight opportunities to work in partnership with other organisations and in jointly funded programs. Many interventions have a broad range of benefits within the public sector and more widely. These occur for example through better educational performance, improved employment and earnings, and reduced crime. ${ }^{59}$ In some cases the pay-offs are spread over many years. Many interventions are very low cost. The modeling of economic impacts can reveal the importance of critical elements in program design and implementation such as targeting to support take-up among high-risk groups and activities designed to improve educational completion rates ${ }^{58}$ Modifying these may be more cost-effective for some interventions than broadening the population coverage. The economic analyses show that, over and above the gains in health and quality of life, effective mental health promotion interventions can generate very significant economic benefits including savings in public expenditure. ${ }^{58}$ Earlier $_{\text {analyses }}{ }^{57}$ also indicate that interventions targeting parents and pre-school children can be highly effective and cost-effective. They provide a robust case for strengthening investment in mental health promotion in schools, increasing educational opportunities for adults, and a variety of interventions to promote mental health at work.

The UK Government's Department of Health 2011 strategy paper, No Health Without Mental Health, notes the health benefits and associated economic savings of evidence-based interventions to prevent and intervene early with mental illness and promote mental health. ${ }^{60}$ The savings occur in the health sector and across other areas in the short-, medium- and longerterm, and the benefits to be realised are consistent with what people say they want. The UK Government concludes that it makes financial sense to invest in building and maintaining good mental health and resilience for communities, families and individuals (as well as provide effective and affordable services at times when they are needed). The Government recognises that mental health is central to quality of life and economic success, and interdependent with success in improving education, training and employment outcomes and tackling some of the persistent social problems, including homelessness, violence and abuse, and drug use and crime. ${ }^{60,61}$ 
Overall the evidence can be assembled to provide encouragement and examples for non-health and health sectors to promote mental health for mutual benefit. The UK Government's Department of Business, Innovation and Skills in their Foresight Project on Mental Capital and Wellbeing, ${ }^{61}$ showed that governments have tremendous opportunities to create environments in which mental capital (cognitive and emotional resources) and wellbeing flourish, and that failure to act could have severe consequences. The project had three areas of focus: childhood development, mental health and wellbeing at work, and making the most of cognitive resources in older age. Government departments need to work together with each other and with civil society to realise the full benefits.

\section{IMPLEMENTING PROGRAMS AND POLICIES TO PROMOTE MENTAL HEALTH AND WELLBEING}

The Foresight, DataPrev and other projects in several countries demonstrate how mental health may be promoted through the work of education, employment and other community sectors. Improved mental health can in turn assist the sectors with their own outcomes. Mental health and public health experts can recommend strategies for promoting mental health in the work of these sectors; and support the development of partnerships needed to accomplish the work and its evaluation. ${ }^{62}$ This adds incrementally to the evidence base.

The first step in any community or other setting is undertaking a thorough needs assessment, gathering local evidence and opinion about the environmental, social and personal influences on mental health and the main problems that need to be tackled (for example, family violence or poor school attendance) and the potential gains. Local people and experts guide the development of the project partnership, including planning and implementing the identified interventions from a series of evidence-based options. However the challenge of translating evidence into policy and practice and the process to identify and scale up those interventions that are evidence-based, have been noted and remain a key area for development in the field. ${ }^{29,63}$ The use of evidence is critical in guiding decision-making for implementation and while some sources for these are publicly available (e.g., WHO, the US Substance Abuse and Mental Health Services Administration, the Collaborative for Academic Social and Emotional Learning (CASEL) the applicability of any tested program to a different context remains unsolved. In addition, the evidence from effect studies will be only one of a number of factors that will need to be taken into account in the 
decision-making processes. Equally important for policy makers or local coalitions will be the use of different types of evidence including implementation essentials, and other decision-making principles such as social justice, political, ethical and equity issues. Decisions reflect public attitudes and the level of resources available, and are rarely based on health outcomes alone. ${ }^{63}$ The implementation systems in which interventions will work, especially when partnerships are created for this purpose, are critical for success. To implement evidence-informed policy successfully it is important to engage key stakeholders by developing a shared vision, clear goals and objectives for a given intervention, considering the different values and acceptability to the general public of a given implementation decision. ${ }^{17}$

Alongside implementation, a critical step is the plan for evaluation of the intervention and the dissemination of evidence-based practices, with attention to maintaining and improving quality over time ${ }^{64}$ In planning the evaluation, it is critical that pre-determined program goals are matched with appropriate measures and instruments, that the evaluation is independently undertaken from those involved in the implementation partnership, and that evaluation measures combine mid- and long-term impacts. The nature of mental health promotion programs in producing resilience and strengthening overall outcomes is seen over the long-term, ${ }^{65,66}$ as are social and economic outcomes (e.g., educational attainment, sick leave rates, crime). ${ }^{29}$

Developing and maintaining partnerships between different types of organisations is in itself a complex and measurable activity that needs to be continuously monitored to ensure successful implementation. ${ }^{19}$ Promoting mental health is expected to lead to measurable benefits in overall health, quality of life and social functioning..$^{67,68}$

Policymakers are now recognizing in some countries that emphasis can be best placed on adding programs that sharpen the capacity of systems, such as primary health care and school systems to be more attentive to mental health. ${ }^{69}$ The sustainability of mental health programs may relate more to their success as change processes within organizations or communities than to their technological aspects. Their evaluation includes analysis of factors within the program context such as pre-existing attitudes and relationships that could predict why some programs and not others succeed and grow. ${ }^{11,69-71}$

\section{Human rights and promoting mental health}

Respect for and protection of all dimensions of rights (civil, cultural, economic, political, and social dimensions) is fundamental to promoting mental health. ${ }^{72}$ Without the security and freedom provided by these rights it is very difficult to maintain good mental health. The International Bill of 
Human Rights and other UN human rights instruments reflect a set of universally accepted values and principles of equality and freedom from discrimination, and the right of all people to participate in decision-making processes. International human rights standards such as the rights to health, education and freedom from discrimination provide a framework to consider mental health across the range of mental health determinants. Their use can contribute to creating a protective environment, and promotes accountability and use of measures to end discrimination and violence. ${ }^{73}$

By these means international human rights standards can be influential in providing protection for vulnerable groups. Women and children and refugees, for example, are marginalised and discriminated against in many settings and at high risk for poor mental health. ${ }^{72}$ Especially in low-income countries and during emergencies, women are more likely than men to be poor and less able to influence personal or household financial decisionmaking. They are more likely to experience violence and coercion from an intimate partner or other family member. Women are also less likely to have access to the protective factors of full participation in education, paid employment and political decision-making. ${ }^{33}$ Countries need to adopt specific measures to monitor, safeguard and realise their rights: including the right to goods, services, conditions and facilities that are conducive to mental health. ${ }^{72}$

The close interaction between mental health and human rights is illustrated by the role of mental health and psychosocial support (MHPSS) programs in protecting human rights during an emergency. The MHPSS programs now commonly integrated in humanitarian assistance programs include many elements that are designed to promote the population's mental health or do so as a desirable side-effect. ${ }^{73,74}$ The MHPSS programs are designed to improve fairness, dignity and participation of the local population. They help people to realise rights and reduce violations. Access to housing, water and sanitation for at-risk groups increases their chances of being included in food distributions, improves health and reduces risks of discrimination and abuse. Providing life skills and livelihoods support to women and girls may reduce their risk of having to use survival strategies such as prostitution with added risks of human rights violations.

Other social interventions outside the health sector that are relevant in humanitarian settings include: (re)starting schooling; organising child friendly spaces; family reunification programs; economic development initiatives and involving existing cultural and religious resources. A basic psychological intervention that may be made available outside the health sector is teaching listening and psychological support skills to a non-health 
community worker. Most of the social and psychological interventions require a thorough understanding of the sociocultural context, which outsiders typically do not have. ${ }^{73,75}$ Future research needs to examine more closely the extent to which these broad social interventions influence individual and communal recovery from traumatic stress reactions and prevent more sustained morbidity. Research is also needed to identify more accurately the personal, social, and cultural factors that encourage natural recovery from immediate stress reactions and those that predict chronicity and disability ${ }^{76,77}$ This agenda emphasises the need for practical knowledge. It requires good alignment between researchers and practitioners, attention to the perspectives of affected populations, and sensitivity to their situation.

\section{PROMOTING MENTAL HEALTH AND DEVELOPMENT IN RESOURCE-POOR COUNTRIES}

Leading proponents recently commented that: “. . there is a growing body of evidence on how mental health promotion across the lifespan can mediate positive health outcomes for people in scarce-resource contexts. Given the potential to break the intergenerational cycle of poverty and mental ill-health and promote human and broader socio-economic development in (resourcepoor countries), mental health promotion can no longer be ignored in these contexts. Placing mental health promotion on the development agenda of (resource-poor countries), is a challenge that requires advocacy across multiple sectors..."11(p.212) The close connections between mental health and other aspects of health and productivity mean that promoting mental health is a necessity in low-income as well as high-income countries. ${ }^{78}$

International cooperation can help generate and disseminate further evidence in resource-poor countries. A full spectrum of research methods including qualitative studies allows investigation of the principles, working mechanisms and effect moderators as well as program outcomes. Step by step, this will build a valid evidence base for the country or community in question. ${ }^{79}$

\section{NATIONAL AND INTERNATIONAL POLICIES, PROGRAMS AND PROJECTS}

Development of the field of mental health promotion, overlapping with initiatives in primary prevention, has progressed steadily over recent decades, Advocacy, research, policymaking, program development and implementation have been achieved by people in many countries and organisations. 
Examples are: pioneering work in Scandinavia, especially in Finland (with the leadership of Drs. Ville Lehtinen and Eero Lahtinen among others); the development of national and regional programs and policies in the UK, US (including Surgeon-General David Satcher's report of 1999), Scotland, Ireland, Canada, Australia, New Zealand, Thailand and other countries; international work of the WHO, OECD and the European Commission, and non-government organizations such as the World Economic Forum, International Union for Health Promotion and Education, World Federation for Mental Health, World Psychiatric Association, Clifford Beers Foundation, the Carter Center and others; and the work of projects such as DataPrev in Europe and Foresight in the UK. The foundational contribution of prevention science in the US with leaders such as George Albee and Sheppard Kellam is reflected in influential reports from the Institute of Medicine and numerous other scientific publications, program papers and policies. The US Centers for Disease Control and Prevention have recently published a Public Health Action Plan to Integrate Mental Health Promotion and Mental Illness Prevention with Chronic Disease Prevention 2011-2015, illustrating the mutual benefits for the control of non-communicable diseases and the broader field of health promotion. International journals in the field include Mental Health Promotion International, Global Health Promotion, and Advances in School Mental Health Promotion. The field has advanced most strongly in high-income countries although the needs are even greater where resources are fewer. The next step is to develop international cooperation and support for worldwide research and development in the field.

\section{CONCLUSIONS}

Governments and opinion leaders in many countries remain poorly aware, despite these efforts, of the way that poverty, trauma, dislocation and social disadvantage affect mental health. Decision makers tend to have little information about the mental health of the population and how it is affected by the policies and practices they introduce across education, employment, social development and other sectors. Nor are they likely to be wellinformed about the evidence-based options for promoting mental health and wellbeing at a population level. There is a limited understanding of mental health and mental illness in most communities worldwide.

However, the field of mental health promotion is evolving rapidly. Recent national and international initiatives focus on wellbeing as a measure of national success. Evidence on the effectiveness and costeffectiveness of interventions promoting mental health is growing and now 
used in policymaking by several governments. Population needs and responses after major disasters internationally emphasise the links between mental health and human rights and the moral as well as practical value of population interventions to promote mental health. Governments and communities in some countries are also becoming more aware of the mutual interactions between mental and physical health status and behavior.

The combined effect of these recent developments is to raise community awareness of the need for collaboration between health and non-health sectors in promoting mental health; and the relevance of mental health to social development and social problems. The idea is taking root that promoting mental health and wellbeing will contribute to ameliorating social problems such as community and family violence. Experience is growing with the development of partnerships and implementation of interventions across welfare, education, health, urban and rural planning, business and other sectors in countries of all types. Wider innovation, adaptation and evaluation of programs is now required, especially in lowincome countries.

About the Authors: Professor Helen Herrman is an Australian psychiatrist and public health physician. She is Professor of Psychiatry at Orygen Youth Health Research Centre and Centre for Youth Mental Health, The University of Melbourne, and Director of the World Health Organization (WHO) Collaborating Centre for Mental Health in Melbourne. She is National Health and Medical Research Council (Australia) Practitioner Fellow, and Honorary Fellow of the World Psychiatric Association (WPA), having served as WPA Secretary for Publications from 2005 to 2011. She is President Elect of the Pacific Rim College of Psychiatrists 2012-2014 and Chair of the Global Consortium for the Advancement of Prevention and Promotion in Mental Health. From 1992-2005, she was Professor and Director of Psychiatry in St Vincent's Health Melbourne and The University of Melbourne. In 2001-2002 she was acting regional adviser in mental health for the WHO's Western Pacific Region. For several years up to 2003 she served as a member of the Board of Trustees for the Victorian Health Promotion Foundation (VicHealth) and has been involved in collaborative activities between WHO, VicHealth and the University of Melbourne in the field of mental health promotion.

Dr. Eva Jané-Llopis is Director of Health Programmes at the World Economic Forum. She is a specialist in health promotion and mental health, with expertise in policy making, evidence development, implementation and evaluation of public mental health and chronic diseases, having worked over the years in leading positions with academia, government, the European Commission and the World Health Organization. She has led large research projects and think tanks, is member of several advisory boards, has been keynote speaker in major international conferences, has published extensively, and has led the development of international networks and initiatives.

Conflicts of Interest: None declared. 


\section{REFERENCES}

1. World Health Organization. WHO MIND - Mental Health in development. WHO. Available from URL: http://www.who.int/mental_health/policy/en/ (Accessed 15 July 2012).

2. Samarasekera U. Jim Kim takes the helm at the World Bank. Lancet. 2012; 380:15-7.

3. Wilkinson R, Pickett K. The Spirit Level: Why More Equal Societies Almost Always do Better. London: Allen Lane/Pengiin; 2009.

4. Sachs JD. Health in the developing world: achieving the Millennium Development Goals. Bull World Health Organ. 2004;82:947-9; discussion 50-2.

5. Sachs JD, McArthur JW. The Millennium Project: a plan for meeting the Millennium Development Goals. Lancet. 2005;365:347-53.

6. Miranda JJ, Patel V. Achieving the Millennium Development Goals: does mental health play a role? PLoS Med. 2005;2:e291.

7. Desjarlais R, Eisenberg L, Good B, Kleinman A. World Mental Health: Problems and Priorities in Low-Income Countries. New York, NY: Oxford University Press; 1995.

8. Prince M, Patel V, Saxena S, Mario Maj, Maselko J, Phillips M, et al. No health without mental health: a slogan with substance. The Lancet Series on Global Mental Health. Lancet. 2007.

9. Ludwig J, Duncan GJ, Gennetian LA, Katz LF, Kessler RC, et al. Neighborhood effects on the long-term well-being of low-income adults. Science. 2012;337: 1505-10.

10. World Health Organization. Mental health and development: targeting people with mental health conditions as a vulnerable group. Geneva: WHO; 2010.

11. Petersen I, Bhana A, Flisher AJ, Swartz L, Richter L, (editors). Promoting Mental Health in Scarce-Resource Contexts: Emerging Evidence and Practice. South Africa: HSRC Press; 2010.

12. Vaillant GE. Positive mental health: is there a cross-cultural definition? World Psychiatry. 2012;11:93-9.

13. Fisher M, Baum F. The social determinants of mental health: implications for research and health promotion. Aust N Z J Psychiatry. 2010;44:1057-63.

14. Sartorius N. Universal strategies for the prevention of mental illness and the promotion of mental health. In: Jenkins R, Ustun TB, (editors). Preventing Mental Illness: Mental Health Promotion in Primary Care. Chichester: John Wiley \& Sons; 1998. p.61-7.

15. Kleinman A. Global mental health: a failure of humanity. Lancet. 2009;374: 603-4.

16. Herrman H, Saxena S, Moodie R, (editors). Promoting Mental Health: Concepts, Emerging Evidence, Practice. Geneva: World Health Organization; 2005.

17. Barry M, Jenkins R. Implementing Mental Health Promotion: Churchill Livingstone Elsevier; 2007. 
18. Friedli L. Mental health, resilience and inequalities. Copenhagen: World Health Organization Europe; 2009.

19. Kellam SG. Developing and maintaining partnerships as the foundation of implementation and implementation science: reflections over a half century. Adm Policy Ment Health. 2012;39:317-20.

20. World Health Organization. Mental health: strengthening mental health promotion. Fact Sheet 220. WHO; 2007.

21. Sturgeon S, Orley J. Concepts of mental health across the world. In: Herrman H, Saxena S, Moodie R, (editors). Promoting Mental Health: Concepts, Emerging Evidence, Practice. Geneva: World Health Organization; 2005. p.50-69.

22. Anderson P, Cooper C, Layard R, Litchfield P, Jane-Llopis E. Well-being and global success: a report prepared by the World Economic Forum Global Agenda Council on Health \& Well-being. Geneva: World Economic Forum; 2012.

23. New Economics Foundation. Well-being evidence for policy: A review. London: NEF; 2012.

24. Organization for Economic Co-operation and Development. Better Life Initiative: measuring well-being and progress. OECD. Available from UEL: http://www.oecd.org/document/0/0,3746,en_2649_201185_47837376_1_1_ 1_1,00.html (Accessed 15 july 2012).

25. United Nations. The world we want. Political Declaration Rio+20 Summit. UN; 2012.

26. Holtz TH, Holmes SM, Stonington S, Eisenberg L. Health is still social: contemporary examples in the age of the genome. PLoS Med. 2006;3:e419.

27. Lund C, De Silva M, Plagerson S, Cooper S, Chisholm D, et al. Poverty and mental disorders: breaking the cycle in low-income and middle-income countries. Lancet. 2011;378:1502-14.

28. Patel V, Kleinman A. Poverty and common mental disorders in developing countries. Bull World Health Organ. 2003;81:609-15.

29. Jane-Llopis E, Anderson P, Stewart-Brown S, Weare K, Wahlbeck K, et al. Reducing the silent burden of impaired mental health. J Health Commun. 2011;16 Suppl 2:59-74.

30. Rogers A, Pilgrim D. Mental Health and Inequality. Basingstoke: Palgrave Macmillan; 2003.

31. Rutz W. Social psychiatry and public mental health: present situation and future objectives. Time for rethinking and renaissance? Acta Psychiatr Scand Suppl. 2006;429:95-100.

32. Commision on Social Determinants of Health. Closing the gap in a generation: health equity through action on the social determinants of health. Final Report of the CSDH. Geneva: World Health Organization; 2008.

33. Fisher J, Herrman H. Gender, social policy and implications for promoting women's mental health. In: Chandra P, Herrman H, Fisher J, Kastrup M, Niaz U, et al., (editors). Contemporary Topics in Women's Mental Health. Chichester: Wiley-Blackwell; 2009. p.499-506. 
34. Patel V, Swartz L, Cohen A. The evidence for mental health promotion in developing countries. In: Herrman H, Saxena S, Moodie R, (editors). Promoting Mental Health: Concepts, Emerging Evidence, Practice. Geneva: World Health Organization; 2005. p.189-202.

35. World Health Organization. Mental health: new understanding, new Hope. The World Health Report. Geneva: WHO; 2001.

36. Sartorius N. Stigma and mental health. Lancet. 2007;370:810-1.

37. Stuart H. Fighting the stigma caused by mental disorders: past perspectives, present activities, and future directions. World Psychiatry. 2008;7:185-8.

38. Henderson C, Thornicroft G. Stigma and discrimination in mental illness: time to change. Lancet. 2009;373:1928-30.

39. Rutter M. Implications of resilience concepts for scientific understanding. Ann N Y Acad Sci. 2006;1094:1-12.

40. Herrman H, Stewart DE, Diaz-Granados N, Berger EL, Jackson B, Yuen T. What is resilience? Can J Psychiatry. 2011;56:258-65.

41. Cicchetti D. Resilience under conditions of extreme stress: a multilevel perspective. World Psychiatry. 2010;9:145-54.

42. Shonkoff JP, Boyce WT, McEwen BS. Neuroscience, molecular biology, and the childhood roots of health disparities: building a new framework for health promotion and disease prevention. JAMA. 2009;301:2252-9.

43. Gunnar MR, Fisher PA. Bringing basic research on early experience and stress neurobiology to bear on preventive interventions for neglected and maltreated children. Dev Psychopathol. 2006;18:651-77.

44. Anderson P, Harrison O, Cooper C, Jané-Llopis E. Incentives for health. J Health Commun. 2011;16:107-33.

45. Herrman H, Moodie R, Saxena S. Mental health promotion. In: Heggenhougen K, Stella Q, (editors). International Encyclopedia of Public Health. San Diego: Academic Press; 2008. p.406-18.

46. Mittelmark MB, Puska P, O'Byrne D, Tang KC. Health promotion: a sketch of the landscape. In: Herrman H, Saxena S, Moodie R, (editors). Promoting Mental Health: Concepts, Emerging Evidence, Practice. Geneva: World Health Organization. p.18-34.

47. Lahtinen E, Joubert N, Raeburn J, Jenkins R. Strategies for promoting the mental health of populations. In: Herrman H, Saxena S, Moodie R, (editors). Promoting Mental Health: Concepts, Emerging Evidence, Practice. Geneva: World Health Organization; 2005. p.226-42.

48. Patel V, Flisher AJ, Nikapota A, Malhotra S. Promoting child and adolescent mental health in low and middle income countries. J Child Psychol Psychiatry. 2008;49:313-34.

49. Jolly R. Early childhood development: the global challenge. Lancet. 2007;369: 8-9.

50. Stewart-Brown SL, Schrader-McMillan A. Parenting for mental health: what does the evidence say we need to do? Report of Workpackage 2 of the DataPrev project. Health Promot Int. 2011;26 Suppl 1:110-28. 
51. Kramer MS, Kakuma R. Optimal duration of exclusive breastfeeding. Cochrane Database Syst Rev. 2012;8:CD003517.

52. Konner M. The Evolution of Childhood. Cambridge, MA: Harvard University Press; 2010.

53. Richards M, Hardy R, Wadsworth ME. Long-term effects of breast-feeding in a national birth cohort: educational attainment and midlife cognitive function. Public Health Nutr. 2002;5:631-5.

54. Read J, Bentall RP. Negative childhood experiences and mental health: theoretical, clinical and primary prevention implications. Br J Psychiatry. 2012;200:89-91.

55. Young and Well Cooperative Reseach Centre. Available from URL: http:// www.yawcrc.org.au (Accessed 16 July 2012).

56. Burns J, Morey C, Lagelee A, Mackenzie A, Nicholas J. Reach Out! Innovation in service delivery. Med J Aust. 2007;187:S31-4.

57. Friedli L, Parsonage M. Mental Health Promotion: Building an Economic Case: Northern Ireland Association for Mental Health (NIAMH); 2007.

58. Knapp M, McDaid D, (editors). Mental health promotion and mental illness prevention: the economic case. London: Personal Social Services Research Unit, London School of Economics and Political Science; 2011.

59. Aos S, Lieb R, Mayfield J, Miller M, Pennucci A. Benefits and costs of prevention and early intervention programs for youth. Olympia, WA: Institute for Public Policy; 2004. Available from URL: http://www.wsipp.wa.gov/ rptfiles/04-07-3901a.pdf (Accessed 7 December 2012).

60. HM Government. No health without mental health: a cross-government mental health outcomes strategy for people of all ages. Supporting Document - The economic case for improving efficiency and quality in mental health. London: Department of Health, UK; 2011.

61. Beddington J, Cooper CL, Field J, Goswami U, Huppert FA, et al. The mental wealth of nations. Nature. 2008;455:1057-60.

62. Saxena S, Jane-Llopis E, Hosman C. Prevention of mental and behavioural disorders: implications for policy and practice. World Psychiatry. 2006;5:5-14.

63. Jané-Llopis E, Katschnig H, McDaid D, Wahlbeck K. Evidence in decision making for mental health. Health Promot Int. 2011;26:140-6.

64. Walker L, Verins I, Moodie R, Webster K. Responding to the social and economic determinants of mental health: a conceptual framework for action. In: Herrman H, Saxena S, Moodie R, (editors). Promoting Mental Health: Concepts, Emerging Evidence, Practice Geneva: World Health Organization; 2005. p.89-105.

65. Eckenrode J, Campa M, Luckey DW, Henderson CR, Jr., Cole R, et al. Longterm effects of prenatal and infancy nurse home visitation on the life course of youths: 19-year follow-up of a randomized trial. Arch Pediatr Adolesc Med. 2010;164:9-15. 
66. Donelan-McCall N, Eckenrode J, Olds DL. Home visiting for the prevention of child maltreatment: lessons learned during the past 20 years. Pediatr Clin North Am. 2009;56:389-403.

67. Zubrick SR, Kovess-Masfety V. Indicators of mental health. Geneva: WHO. In: Herrman H, Saxena S, Moodie R, (editors). Promoting Mental Health: Concepts, Emerging Evidence, Practice. Geneva: World Health Organization; 2005. p.148-68.

68. Wiseman J, McLeod J, Zubrick SR. Promoting mental health and well-being: integrating individual, organisational and community-level indicators. Health Promot J Austr. 2007;18:198-207.

69. Hawe P, Riley T. Developing sustainable programs: theory and practice. In: Herrman H, Saxena S, Moodie R, (editors). Promoting Mental Health: Concepts, Emerging Evidence, Practice. Geneva: World health Organization; 2005. p.252-63.

70. Rowling L, Taylor A. Intersectoral approaches to promoting mental health. In: Herrman H, Saxena S, Moodie R, (editors). Promoting Mental Health: Concepts, Emerging Evidence, Practice. Geneva: World Health Organization; 2005. p.264-83.

71. Swartz L. Contextual issues. In: Petersen I, Bhana A, Flisher AJ, Swartz L, Richter L, (editors). Promoting Mental Health in Scarce-Resource Contexts: Emerging Evidence and Practice. South Africa: HRCS Press; 2010. p.49-59.

72. Drew N, Funk M, Pathare S, Swartz L. Mental health and human rights. In: Herrman H, Saxena S, Moodie R, (editors). Promoting Mental Health: Concepts, Emerging Evidence, Practice. Geneva: World Health Organization; 2005.

73. Inter-Agency Standing Committee. IASC Guidelines on Mental Health and Psychosocial Support in Emergency Settings Geneva: IASC; 2007.

74. Herrman H. Promoting mental health and resilience after a disaster. J Exp Clin Med. 2012;4:82-7.

75. van Ommeren M, Saxena S, Saraceno B. Aid after disasters. BMJ. 2005;330: 1160-1.

76. Silove D, Bryant R. Rapid assessments of mental health needs after disasters. JAMA. 2006;296:576-8.

77. Tol WA, Patel V, Tomlinson M, Baingana F, Galappatti A, et al. Research priorities for mental health and psychosocial support in humanitarian settings. PLoS Med. 2011;8:e1001096.

78. Herrman H, Swartz L. Promotion of mental health in poorly resourced countries. Lancet. 2007;370:1195-7.

79. Saxena S, Herrman H, Moodie R, Saraceno B. Conclusions: the way forward In: Herrman H, Saxena S, Moodie R, (editors). Promoting Mental Health: Concepts, Emerging Evidence, Practice. Geneva: World Health O; 2005. 